\title{
Increased Risk of Bartonella Infections in Humans
}

\section{Bogdanka Andric ${ }^{1 *}$, Aleksandar Velkovski', Milan Jovanovic ${ }^{1}$, Mosa Markovic ${ }^{2}$, Mileta Golubovic ${ }^{3}$}

\author{
${ }^{1}$ Medical Faculty University of Montenegro, Podgorica, Montenegro \\ ${ }^{2}$ Department of Infectious Diseases, Medical Center, Pancevo, Serbia \\ ${ }^{3}$ Institute for Pathology, Medical Faculty University of Montenegro, Podgorica, Montenegro \\ Email: *bogdankaandric0@gmail.com
}

How to cite this paper: Andric, B., Velkovski, A., Jovanovic, M., Markovic, M. and Golubovic, M. (2018) Increased Risk of Bartonella Infections in Humans. Open Journal of Clinical Diagnostics, 8, 25-45. https://doi.org/10.4236/ojcd.2018.83004

Received: May 31, 2018

Accepted: September 25, 2018

Published: September 28, 2018

Copyright ( $\odot 2018$ by authors and Scientific Research Publishing Inc. This work is licensed under the Creative Commons Attribution International License (CC BY 4.0).

http://creativecommons.org/licenses/by/4.0/

(c) (i) Open Access

\begin{abstract}
Bartonellosis has emerging zoonoses of the Vector Borne Diseases (VBD) complex. Progress in evolution and changes of causer, enabled the expansion, and increased number of clinically manifest forms of disease appearance of severe disseminated forms of infections and co-infections in humans, difficult for diagnosis, therapy and prognosis. The Bartonellosis may have a benign and self-limiting evolution in a host, or potentially fatal infections. Etiological agents can provoke a granulomatous or an angioproliferative histology damages. In severely immunodeficient cases (pulmonary tuberculosis, carcinomatosis, HIV infection, patients who underwent organ transplantation etc.), Bartonella infections can be difficult and often with unpredictable course of the fatal prognosis. Present the large specter of clinical manifestations: prolonged fever, erythema nodosum like syndrome, and the other skin manifestations, sub-acute bacterial endocarditis, difficult pulmonary disturbances, bacillary angiomatosis (BA) and hepatic peliosis (HP), bacteriemia or a combination of these. In period 2007-2015 on Clinic for Infectious Diseases in Podgorica, 25 cases with Bartonella infection were diagnosed. In total sample, the most frequent were diagnosed CSD in 19 cases. During 2015 in two cases with HIV/AIDS infection, BA was diagnosed, and in four cases PH was diagnosed.
\end{abstract}

\section{Keywords}

Bartonellosis, Emerging, Diagnosis, Prognosis

\section{Introduction}

Bartonellosis has emerging zoonoses of the Vector Borne Diseases (VBD) com- 
plex [1] [2] [3] [4]. Progress in evolution and changes of infectious agents enabled the expansion, increased number of clinically manifest forms of disease, appearance of severe disseminated forms of infections and co-infections in humans, difficult for diagnosis, therapy and prognosis [5] [6] [7] [8].

Genus Bartonella (B) presents small Gram-negative bacteriae, identified as causers of humans infection until 1990 (B. hensellae), 1992 (B. quintana). Of the broad spectrum of known Bartonella species (spp.) the numerous newly species that may cause human disease is eddied: $B$. vinsoni subsp. berkhoffii, $B$. claridgeiae, B. tamiae, B. rochalimae, B. elisabetae, B. koehlerae, B. graham and B. balsatica [9] [10]. Candidates $B$. mayotimonensis and $B$. melophagi where representively isolated from aortic valve in-patient with culture negative endocarditis and in the blood of patients with symptoms are consistent with bartonellosis [11] [12]. Candidate's $B$. ancashi was isolated from the blood of a patient with Verruga peruana in Peru [13]. B. hensellae, B. quintana, and B. bacilliformis has been isolated most frequent from human's infections in wide array of clinical syndromes [14] [15] [16]. Recent research confirms co-infective participation of the different Bartonella spp. and subspecies in common infections [17] [18] [19] and Bartonella spp. with large specter of VBD zoonotic agents in human co-infections [20] [21] [22] [23] [24].

Bartonellosis are diseases known even from ancient period on basis the clinical picture and the assumed relationship with animals-natural reservoirs of pathogens [25] [26]. Newel epidemiological data present as Bartonellosis has wide spread in the World, including wild and domestic mammals, especially in areas with hot and humid climate [27] [28].

Often the transmission of Bartonella spp. in humans occurs by traumatic contact with infected animals (cat scratch, cat bite, likely), by vectors-cat fleas (Ctenocephalides felids) or other blood-sucking arthropods (e.g. Sand fly, Phlebotomies, Human louse). For some Bartonella species, the vectors are known [28]-[33]. In 3.6\% of cases method of transmission has not been known.

Bartonella agents have detected in several tick species, including Ixodes (Ix) ricinus, Ix. scapularis, Ix. Persulcatus, Dermacentor reticulatus, Rhipicephalus sanguineus [34] [35] [36] [37], but their competence in disease transmission is unclear. Data of the many epidemiological studies present co-infective participation of Bartonella species in $28 \%$ of cases with chronic Lyme borreliosis (LB) [38]. The controversial diagnosis of chronic Lyme disease is often giving to patients with prolonged, medically unexplained physical symptoms. Many such patients are also treating for chronic co-infections with Babesia, Anaplasma, or Bartonella in the absence of typical presentations, objective clinical findings, or laboratory confirmation of active infection [39] [40]. From a number isolates of borrelia burgdorferi (bb), has found two main fractions of heat shock proteins (HSP60 and HSP70), which cross-react with antigens of other microorganisms, pointed the possibilities of transmission of Bartonella agents through bb. The fact of exist co-infective forms of disease and knowledge's that Bartonella in 
natural condition, in natural hosts and vectors can be shared their DNA with the different agents of the VBD complex (e.g. B. burgdorferi, Babesia spp., Rickettsiae and Bartonella spp.), opened a new chapter in the study of Bartonellosis. Types of potential more participants in co-infections, determines geographical distribution of infective agents in natural foci [38] [39] [40] [41].

Experimentally is demonstrated that Ix. ricinus can transmit $B$. henselae during a blood meal. However, the replication of bacteria has rarely reported in the ticks, we do not support the hypothesis that ticks are natural competent vectors of Bartonella spp. [32] [34] [35] [36].

In the study of the 386 tick specimens collected in spring 2009 from migratory birds on the Mediterranean area was positive for RNA of Bartonella in $98.9 \%$ of the ticks [38]. There present evidence that Bartonella can replicate within ticks and no definitive evidence of transmission by a tick to a vertebrate host.

The pathogenesis of Bartonrlla infection has not fully known. The Bartonellosis may have a benign self-limiting evolution in a host, or potentially fatal infection. The causers can provoke a granulomatous or an angioproliferative histopathology damages. There are two conceptually distinct Bartonella-associated syndromes: bacteriemia (in the absence of focal tissue vascular proliferative response) and the tissue infection bacillary angiomatosis (BA) or hepatic peliosis (HP) associated with angiogenic response [42] [43] [44].

Human Bartonellosis present several diseases with a rapidly increasing clinical specter [14] [16]. The known manifestations present: cat scratch disease (CSD) [26], bacillary angiomatosis (BA) [43], hepatic pelidosis (HP) [42], Trench fever. Today Oroya fever and Verruga peruana has called Carrion's disease and the others [26].

Along with these diseases, recurrent bacteriemia, endocarditis, septicemia, erythema nodosum, erythema multiforme, trombocytopenic purpura and other syndromes has reported that caused of Bartonella spp. [11] [12] [16] [21] [22]. More studies show that co-infective relations between different Bartonella spp. are frequent. B. mayotimensis and B. melophagi has often founded at culture negative endocarditis, while $B$. claridge and $B$. henselae has found in arthritis and neuroretinitis [11] [12] [15] [16] [20] [23].

In severely immunocompromised cases with pulmonary tuberculosis, carcinomatosis, HIV infection, aplastic anemia treated with corticosteroids, systemic lupus erythematosus, patients who underwent organ transplantation, Bartonella infections can be difficult and often with unpredictable course of the fatal prognosis. In late stage of HIV infected patients present large specter of clinical manifestations: prolonged fever, erythema nodosum like syndrome, and the other skin manifestations, subacute bacterial endocarditis, with valvular vegetations on echocardiography, in HIV-infected patients with $B$. Quintana, difficult CNS and pulmonary disturbances [44] [45], include BA, PH, bacteriemia or a combination of these. Patients with history of exposure to vectors biting or animal are scratch/bites are in high risk, and required to be tested. 
Antibiotics therapy is necessary for human bartonellosis because a substantial number of patients relapsed after several weeks to two months courses of therapy, and because increasing evidence that most maladies cases of Bartonellosis should be evaluate for additional sites of infection, such as bone marrow, liver, and heart, central nervous system (CNS). For patients with more severe disease should be treated initially with one or two antibiotics intravenous (iv) and receive a minimum total of four months of antibiotic treatment [46] [47].

The diagnosis of Bartonellosis has difficult, as opposed to the need to prevent complications and progression of disease in chronic forms. Traditionally serological Indirect Immune Fluorescent method (IIF) and Enzyme liked immunosorbent assay (ELISA) method, and Polymerase Chain Reaction (PCR) assay have been used to diagnose Bartonella, but false negative rates can be high ${ }^{1}$. The novel way to documented Bartonella infection using methods, which are more sensitive. This testing strategy has been important for a broad range of disorders that damaged the cardiovascular, lymphatic, musculoskeletal and CNS systems on the way of Bartonella infection [42].

\section{Methodology}

In period, 2007-2015 on Clinic for Infectious Diseases in Podgorica, Montenegro, were diagnostics in total 25 cases with Bartonella infection. The frequency of diagnosed cases increased significantly in the last two years, when they has registered with the CSD and the first cases of BA and $\mathrm{PH}$ as well as significantly more severe forms of diseases. In the total sample, the most frequent were diagnosed CSD in 19 cases. During 2015 in two cases with HIV/AIDS infection, was diagnosed bacillary angiomatosis (BA), like Kaposi sarcoma, and in four cases peliosis hepatis $(\mathrm{PH})$ was diagnosed.

The investigation used epidemiological, clinical, serological Indirect Immune Fluorescent (IIF), Enzyme Liked Immunosorben Assay (ELISA) methods, Polymerase Chain Reaction (PCR). The ultrasound diagnosis has used for making diagnosis of enlarged lymph nodes, liver and spleen and for monitoring the development of the disease.

In four cases there were extirpated affected lymph glands and performed microbiological and hystopathological analysis. Skin lesions, as if to Kaposi sarcoma was also analyzing histological. If is necessary, where used the other diagnostic methods as komputerising tomography (CT), X-Rey diagnostics and others.

\section{Results}

In our study the largest group of Bartonellosis was represented CSD in 19 cases. The $40 \%$ patients have cities inhabitants, $40 \%$ live in suburban and $20 \%$ in rural locations. Age distribution of patients presents 11 (\%) cases of children population, and adult's population in $8(\%)$ cases. The most CSD cases present a be${ }^{1}$ It has been documented that Bartonella in its natural hosts, vectors, and even in the infected organism, can rinse its proteins and genetic material with the host, hence the unreliability of the serological methods, and the PCR. 
nign, self-limiting disease, but in vulnerable and immune deficient cases, infection present difficult disease. In the clinical specter of CSD, common infective syndromes (fever, malaise, chills, and fatigue) have $78 \%$ of cases. The transitory liver disturbances have registered in $67 \%$ cases. Perinaud oculoglandular syndrome is not registered, but $50 \%$ of patients had conjunctivitis. In total examined group, 19 (100\%) cases with CSD had previous contact with a cat. Primo affect has registered in $75 \%$ cases (Figure 1 ).

In 4 (\%) cases after contact with a cat, possible cat flea's bite, manifested generalized maculo-papular rash (Figure 2).

In addition to the general symptoms in our patients dominant clinical manifestations of CSD has regional enlarged lymph nodes presented in all patients, persisted for several weeks or months then may be it $\mathrm{s}$ spontaneous regression and complete resolution in $75 \%$ cases. In $25 \%$ of cases inflammatory changes in the lymph nodes, manifested hyperplasia, granulomatous inflammation with suppuration and exulcerating glands (Figure 3 ).
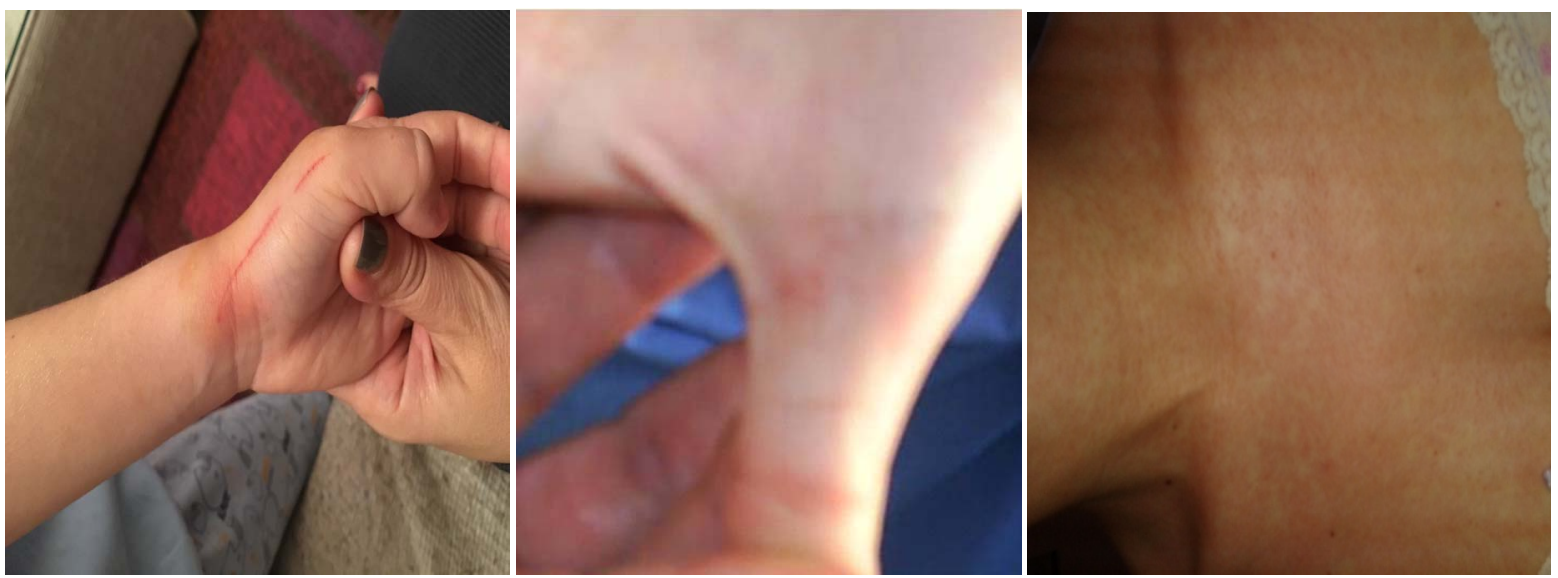

Figure 1. Skin primo affect after cat scratch. On basis their appearances and localization, present indicator of the Bartonella way in CSD infection (Photo documentation of Professor Bogdanka Andric).

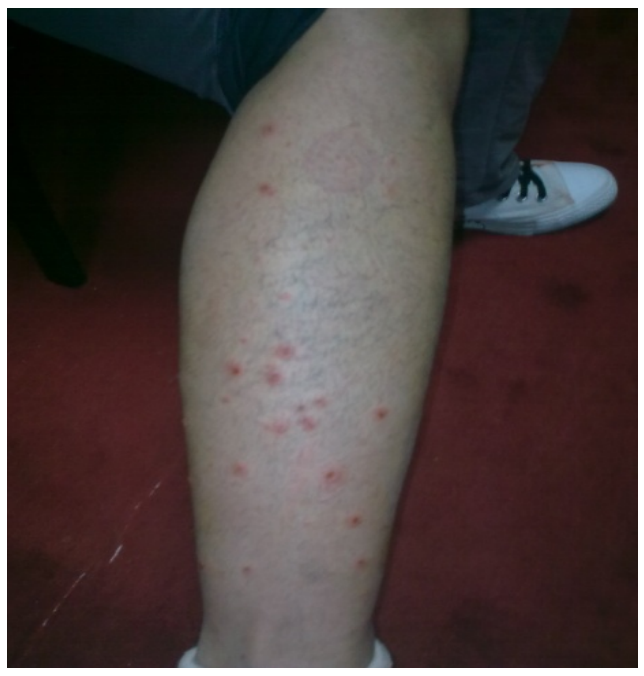

Figure 2. Maculo-papular rash after flea bite in CSD infection (Photo documentation of Profesor Bogdanka Andric). 
Ultrasound diagnosis showed enlarged lymph nodes in axilar and cervical region with the signs of peryadenitis and central coliquation, with suppuration and exulceration (Figure 4).

Results of microbiological and histological analysis emphasized the following characteristics (Figure 5). Microbiological preparates stained by Woirting Sttar were negative.
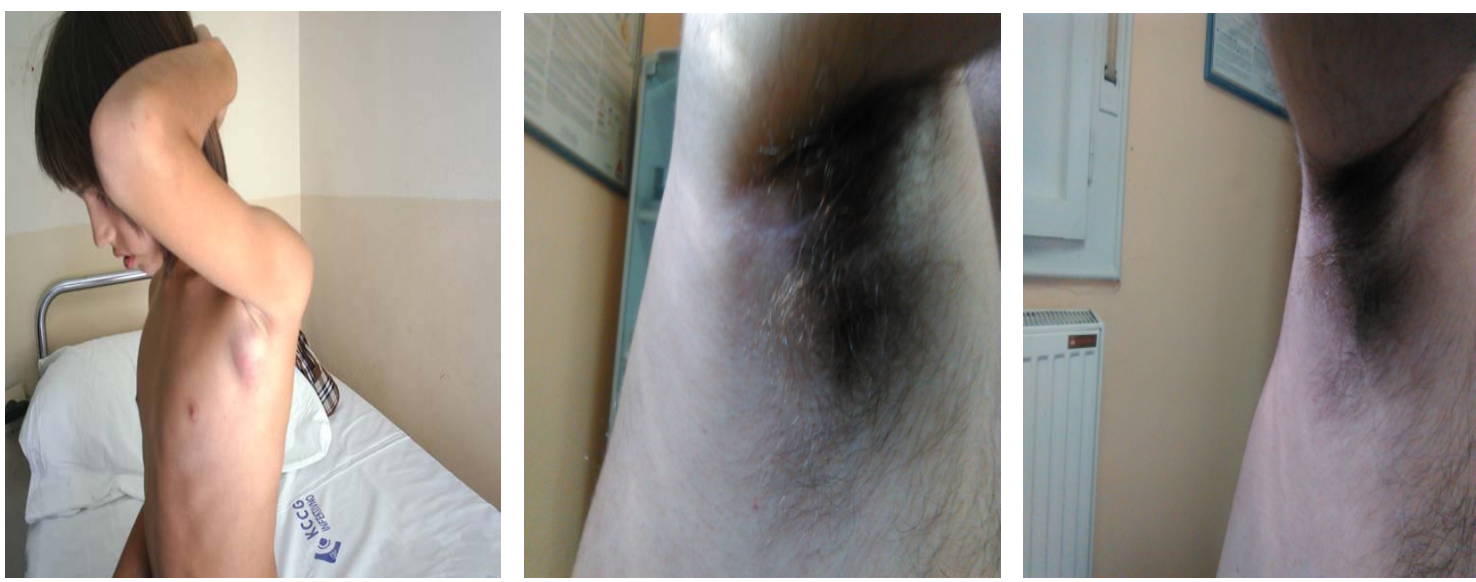

Figure 3. Regional adenopathy becomes apparent 3 - 10 days after infection and it's usually accompanied by fever, chills, malaise, headache, conjunctivitis, pharyngitis, anorexia ((Photo documentation of Prof. Dr. Bogdanka Andric).
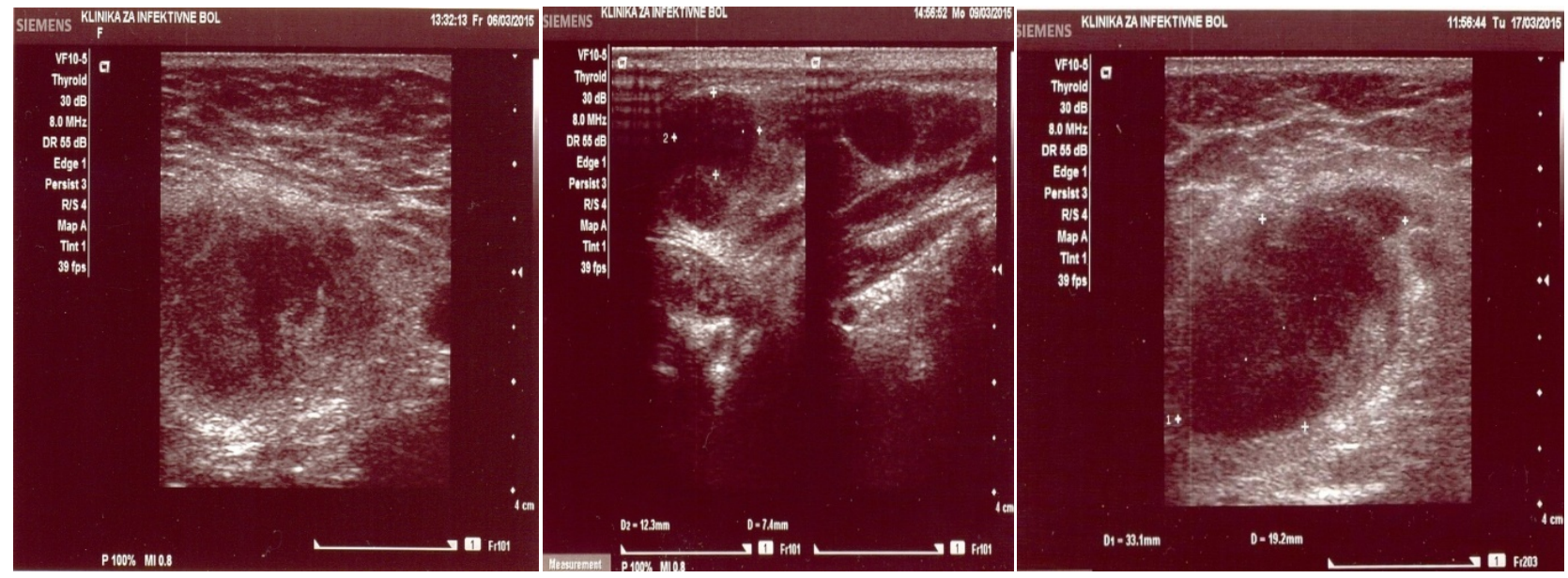

Figure 4. Ultrasound diagnosis: In the central zones of enlarged lymph nodes there are hot spots colliqation (Appendix).
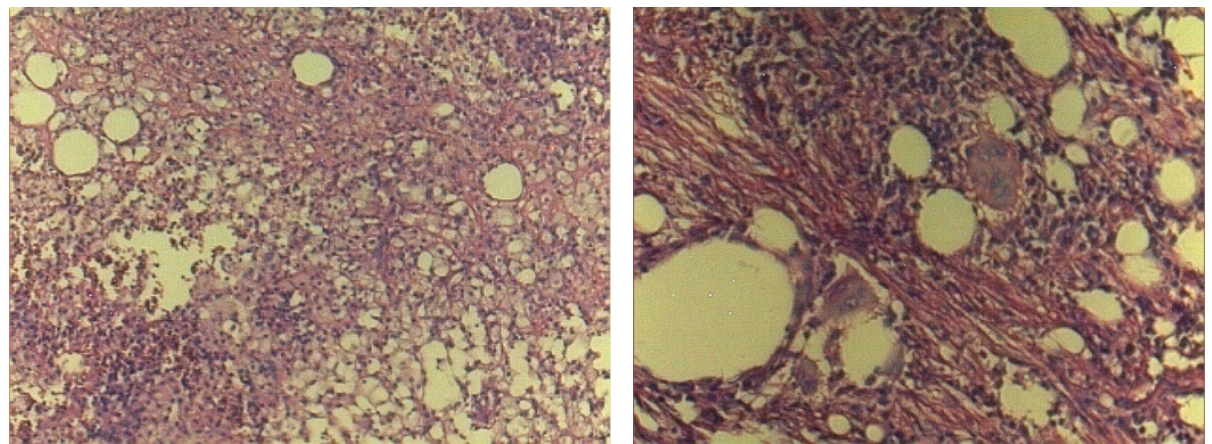

Figure 5. Patohystological diagnosis of enlarged lymph nodes in cat scratch disease (Thanks to Prof Mileta Golubovic). 
Clinical diagnosis: Lymphadenitis chronica granulomatosa (precipue suppurativa).

Macroscopic diagnosis: More lymph nodes, the largest diameter of $3 \times 2.4 \mathrm{~cm}$. On the cross sections is observed more whitish, medium-hard fine focus with central areas of necrosis.

Microscopic diagnosis: Described formation identifies a necrotic granuloma, built of epithelioid histiocytes, rare few multinucleate gigant cells and lymphocytes, surrounded by concentric hyalinised binder. Present peripheral large star-formation in whose centers of mass with abundant eosinophyls granulocytes nuclear detritus (dominance neutrophils).

Conclusion: The morphology of granulomas inflammation in the first place corresponds to of cat scratch disease (CSD).

In 2015 year in Clinic of Infectious Disease in Podgorica, we diagnosed bacillary angiomatosis (BA) in two cases with HIV/AIDS infection, and hepatic peliosis (PH) in 4 cases.

Bacillary angiomatosis (BA) has detected in two man ages of 38 and 24 years, residents in Podgorica. Both patients are known to be HIV positive since 2013, and were not controlled and were not using antiretroviral drugs. The possible ways of Bartonella infection on the epidemiological data were unknown. In both patients pathological changes affected skin, liver and lung. He had been complaining of fever, weight loss of $5-7 \mathrm{~kg}$ in last 3 months, dispnea, abdominal pain, vomiting, anorexia, malaise, lower extremity swelling. An elderly patient has edema of the face and nose with purplish nodules similar to Kaposi sarcoma, which worsened for months before admission to the hospital (Figure 6). Younger patients had extensively characteristic purplich nodules with skin of face, chest and abdomen.

The etiological confirm diagnosis founded by serological methods: Immune fluorescence (IIF) and ELISA assay. Results present IgM and IgG positive antibody against Bartonella henselae in diagnostic titer. Detection of Bartonella DNA in tissue specimens by polymerase chain reaction (PCR) assay or of Bartonella antigens by immune hystochemical methods is diagnostic. For tracing
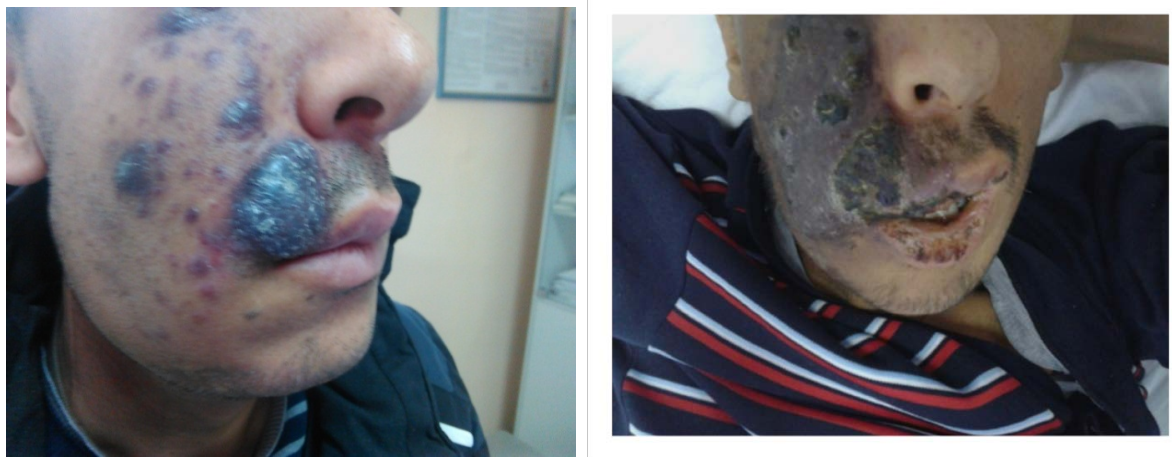

Figure 6. AIDS and B. henselae co-infections. Angioproliferative skin lesion resembling the those of Kaposi sarcoma in our patient. Hystological examination shown shaving disclosed vascular proliferation of capillaries with typical endothelial cells, accompanied by edema, neutrophils, and basophiles infiltrates. 
evolution of disease and therapy, diagnostic methods used CT, Ultrasound diagnosis, X-ray, histopathological examination.

At the physical examination in both patients has registered: distended abdomen with painful, enlarged liver and spleen, and mild as cites. He also had moderate lower limbs edema. Laboratory analyses present leucopenia and anemia, mild elevated levels of serum transaminases. AST (asparat aminotransferase) and ALT (alanin aminotransferase), Lactate dehydrogenase (LDH), total bilirubin, Gamma glutamate transferasis and alkaline phosphates were also elevated. On the Chas X-ray, he had infiltrations of the lung. The CD4 count was $5 / \mathrm{mm}^{3}$ on addmition, and viral load (VL), $>600.000 \mathrm{cop} / \mathrm{ml}$. On ultrasound and CT abdominal examinations is founded the changes in the liver, spleen, pancreas. Mild ascites and bilateral pleural effusion has found. The myelogram displayed dysmyelopoiesis.

Despite therapy with ceftriaxone, ciprofloxacine, trimethoprim-sulfamethoxazole the patient's condition worsened. When an elderly patient fever persisted in irregular spikes, the skin lesions increased in number and size consisting of edematous and livid nodules on the right face and nose and some of the lesions progressed to ulceration. Laboratory analyses get worsted, elevation of the hepatic enzymes, total bilirubin, alkaline phosphates and gamma glutamat transferases.

In third week, there has been a deterioration of disease. Further increase has noted in the liver size, and in the number of erythematous papules with spontaneous bleeding in a few, and worsens in laboratory analyses.

The following abdominal ultrasound showed enlarged liver associated to signs of diffused parenchyma disease. Histology reveals vascular proliferation with the presence of neutrophils adjacent to the blood vessels. Bacteria, is not can be demonstrate by modified silver staining (within-starry silver stain). Detection of Bartonella DNA in tissue managed using Polymerase Chain Reaction (PCR). Lymph nodes were enlarging in the peripancreatic, perihilar, and retroperitoneal regions, as well as ascites and slight enlargement of the spleen. Despite all given therapy he died to the end of the third week of hospitalization.

A few months later the same year Peliosis hepatis (PH) has detected in four cases. In relation to age, it was three children cases, aged of 5, 7 and 9 years, and one case aged of 18 years. Common to all cases were data on close and prolonged contact with cats, in three younger cases with data on reusable scratch and bite of cats, and the absence of symptoms of CSD. The older patient did information that constantly sleeping with their pets (cats) in the same bed.

Common in the clinical presentation of the disease in all patients was prolonged febrile state with a history of weakness, weight loss, and anemia. Enlarged liver and spleen together with the elevated liver enzymes, one of our differential diagnoses was that of liver disease thrombocytopenia, moderate leukocitosis neutrophilia. In patients are registered hiperbillirubinemia. The ultrasound diagnostic was registered enlarged liver and conglomerates of enlarged lymph 
nodes in the heeler liver region (Figure 7).

$\mathrm{CT}$ is variable depending on liver density, but is usually of multiple hypo-attenuating lesions of variable size. Central haemorrhagies may lead to areas of hyper-attenuation and even dystrophic calcification.

Etiological confirmation of diagnosis has founded by serological methods ELISA and IIF, additionally supported by PCR method. Results present IgM and IgG positive antibody against of Bartonella henselae in diagnostic titer.

Disseminated forms of bartonellosis develop in patients infected with immunodeficiency, rare for immune competent cases [18] [19] [20] [43]. In our examined group, transitory, benign respiratory symptoms (pharyngitis, bronchitis) are all patients, and one case with AIDS, bronchopneumonia with uncertain prognosis.

In one case with diagnosed and treated pulmonary tuberculosis, confirmed diagnosis of bartonellosis, at the first moments, present many differential diagnostic problem.

In $2(13.33 \%)$ cases with CSD, in acute phases, with common infective syndromes the symptoms of erythema nodosum are present (Figure 8).
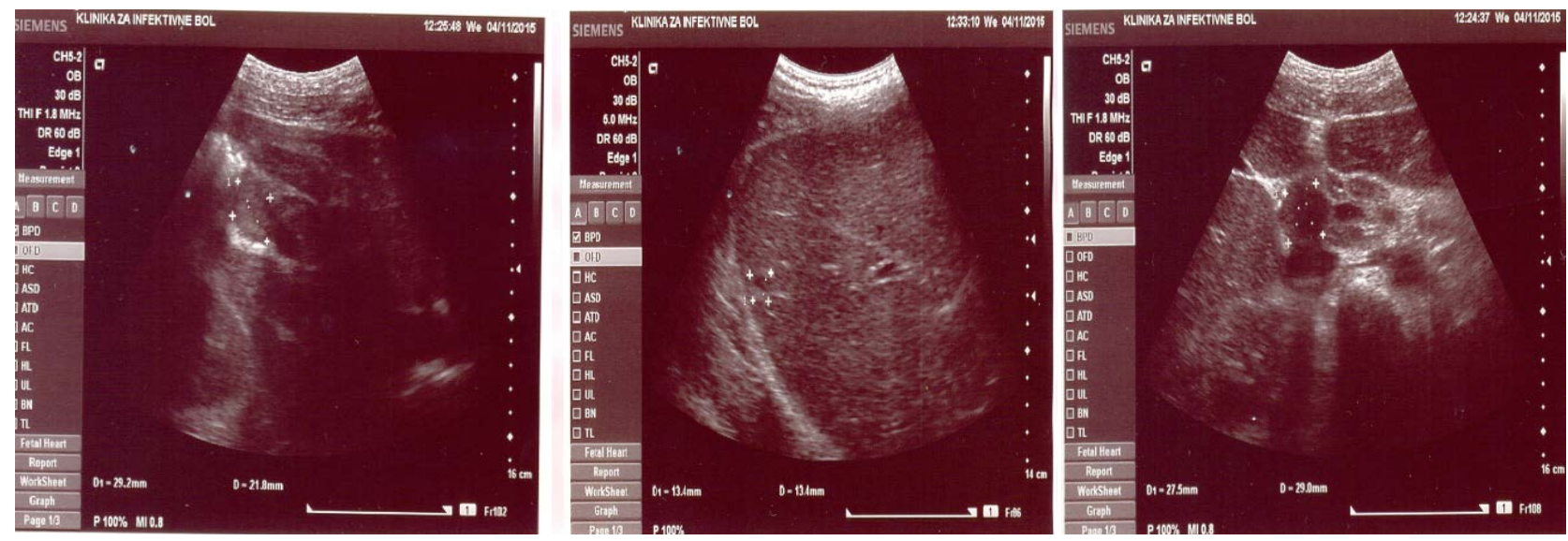

Figure 7. Ultrasound diagnosis of PH in our patient: More focal changes in liver parenchyma. Enlarged lymph nodes in the hillary liver region and para-pancreatic region (Appendix).
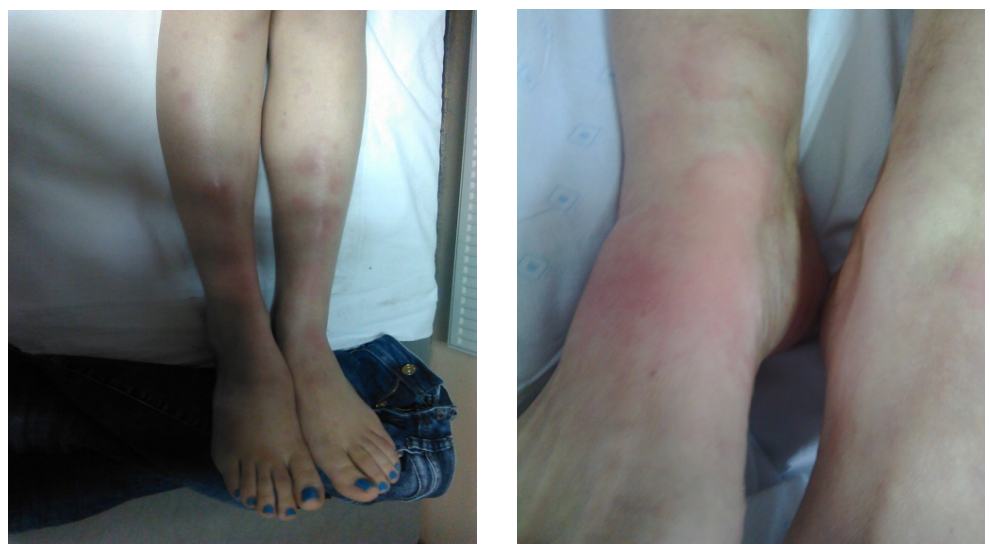

Figure 8. Skin manifest erythema nodosum in two patients with Bartonella infection (Photo documentation of Prof. Dr. Bogdanka Andric). 


\section{Discusion}

Montenegro is an endemic area for a considerable number of VBD. Natural conditions and geographical position (Mediterranean area), changes in environmental characteristics of vectors and infectious agents are main predisposing factors for the expansion and increasing importance of these infections. Resistance to antibiotics additionally complicates disease prognosis [44] [45].

Bartonellosis is zoo-noses in which progress in evolution and changes of infectious agents enabled expansion and appearance of severe disseminated forms of infection and co-infections as demonstrated by investigations in the world and in our study [4] [7] [9] [13] [38] [39]. CSD, BA and PH are entity of Bartonellosis, which has registered in our environment.

In our study, most frequented Bartonella infection is CSD. In addition to the general symptoms, enlarged lymph nodes present dominant clinical manifestations of disease, in all patients [36] [42]. In our study, five patients with BA and $\mathrm{PH}$ also had generalized enlarged lymph nodes. In our examined group, the four patients have disseminated maculopapular rash [19] [35] after positive contact with cat, no data on scratched or bitten by a cat. Based on which data, one could assume that infection may be occur through the bite of cat fleas, possible the other blood sucking vectors, or a consequence of disseminated infection, based to the literature data that at $8 \%$ of patients with CSD $1-8$ week after development-enlarged lymph nodes, begins septic manifestations and complications in various organs and systems.

Disseminated forms of Bartonella infection develop in patients with immunodeficiency, rare for immunecompetent cases [18] [19] [20] [43]. This infection has multisystemic presentation, difficult for diagnosis therapy and prognosis, especially in immunecompromised hosts.

In Central Nervous System (CNS), encephalopathy is an infrequent, but important signs of disease. Persistent intellectual impairment was been reported. Neurologic sequels may remain for weeks and months after infection: encephalitis, neuropathy, neuroretinitis [38] [39] [40]. In peripheral nervous system (PNS) transverse myelitis was describe [28]. The psychiatric disorders have also described [48]. Cerebral fluids (CSF) are not helpful in diagnosis.

Ocular manifestations of bartonellosis present Perinaud oculoglandular syndrome develop in $2 \%$ - $3 \%$ of patients, manifested with the characteristic granulomatous lesion on the conjunctiva and the periocular adenopathy, papillitis. Posterior segment findings include optic neuropathy, neuroretinitis, vitreitis, and others. In our patients, except transitory conjunctivitis, is not registered serious disruption of ocular disturbances.

Bacillary angiomatosis (BA) and bacillary peliosis $(\mathrm{PH})$ are vascular proliferative manifestations of Bartonella infection that occur predominantly in immune deficient patient, rare in immune-competent cases.

BA typically involved the skin and was believe to resemble Kaposi sarcoma, but can affect other organs such as the respiratory tract, bone marrow, lymph 
nodes, adrenal glands, gastrointestinal tract, liver and spleen. The causer's of $\mathrm{BA} / \mathrm{HP}$ are B. henselae and B. quintana. Some studies have described the prevalence of BA in patients with immunodeficiency [1] [2] [4]-[10].

In period of 2012 to 2015, we are studied $50 \mathrm{HIV}$-infected persons, for the detection of co-infective forms of diseases. The spectrum of infective agents, potentially participants in these common basis of HIV infected persons, included intracellular agents, whose reactivation and participation in co-infections with HIV based on declining immunity and potentially reactivation of the spectrum causers such tuberculosis, coxiellosis, brucellosis, micoplasmae pneumonia, Chlamydia, listeriosis, EBV, CMV.

Participation of infectious agent's of VBD complex, in common infective forms of diseases, based on the epidemiological and immunological environment characteristics and evolutionary changes of infectious agents of VBD complex. The geographical area dictates the potential participants in the co-infections. Investigates are covered: Bartonella henselae, B. burgdorferi, Coxiella burneti, Leishmania donovani, Babesia spp. and others.

Peliosis hepatis (PH) is a rare vascular disease. The epidemiology and pathohistology of disease is still unclear [4] [15]. In $80 \%$ of patients passes asymptomatically, and accidentally discovered during ultrasound diagnostics or during the autopsy. It is most often found in the liver, but can also occur in the spleen, bone marrow, the lungs, lymph nodes, kidneys, adrenal glands, and other parts of the gastrointestinal tract.

$\mathrm{PH}$ is an uncommon condition of the sinusoidal system of the liver with enlargement and dilatation resulting in blood-filled cavities with a diameter up to several centimeters. The rare cases, it may be complicated by rupture with resultant bleeding.

It was first report in the early 1950s in patients with tuberculosis, but his also founded in many other pathological conditions such has also been reported in related to drugs and chemicals, bacterial infections, hematological and other malignancies, organ transplanting, and other.

Several publications have appeared leading to a more precise classification of the structural abnormalities in $\mathrm{PH}$, which can be subdivide into a parenchyma form, with enlarged sinusoidal cavities, and a phlebectatic form, which characterized by regular sinusoidal cavities with per sinusoidal fibrosis [16].

In our four cases with $\mathrm{PH}$, clinical diagnosis based on ultrasound diagnosis, and etiologically confirmed diagnosis by serological IIF and ELISA tests and PCR method. These were patients of the children's ages, where not detected none of the above possibilities immunodeficiency, except age and possibly malnutrition.

Isolated Bartonella bacteremia has founded in immunodeficient and immune competent cases this is often sub acute, persisting for months before diagnosis; in one case, at least eight months relapsed before BA was diagnostic.

Rarely Bartonellosis spreads and causes granulomatous hepatitis [20] [30] or 
granulomas in the spleen or bone marrow. In our study in $60 \%$ of patients are registered increase activity of liver enzymes (AST, ALT, LDH), and enlarged liver and the spleen.

On basis, the literature data different pulmonary disturbances in Bartonellosis are present. In our study, the transitory lung disturbances: pharyngitis, bronchitis is frequent. In one immunodeficient case, pulmonary infiltrates are present, contributed to the bad prognosis of disease [40] [41].

Endocarditic-valve replacement is required in approximately $80 \%$ of cases, but overall prognosis is relatively good. It was determined that this manifestation largely belong to co-infective forms of disease, in which participating $B$. helsellae and B. burgdorferi, Rickettsial agents, Coxiella burneti and other [10] [13] [31].

Endocarditis due to $B$. quintana was been reported in both immune compromised and immune competent cases. The presenting symptoms are usually those of sub acute bacterial endocarditis, with malaise, weight loss, and fever. Valvule vegetations are been often demonstrated on echocardiography, as was reported for one HIV-infected patient with B. quintana endocarditis who developed both aortic and mitral valvule vegetations. Because Bartonella organisms are not isolated from routine blood cultures, Bartonella appears to be a cause of culture-negative endocarditis. In our study, endocarditis is not registered.

Erythema nodosum like syndroma, return bacteriemia, osteomyelitis is a rare manifestation in $0.2 \%-0.3 \%$ of patients with Bartonellosis are good prognosis after antibiotics treatment.

B. henselae infection is one of the common causes of fever of unknown origin and prolonged fever in children. In many patients, develop low-grade fever that last several days. One study showed that the absence of adenopathy in patients with CSD has closely related to the presence of prolonged fever or systemic complications [40] [41].

The diagnosis of Bartonella infection in our study has confirmed in all cases, based on epidemiological, clinical, serological and histopathological findings. Serological diagnosis by IIF with a titer 1:64 confirmed diagnosis. Diagnosis should be confirmed with demonstration of a 4-fold rise in antibody levels, initially specific immunoglobulin M (IgM), followed by immunoglobulin G (IgG). Positive results have matched with the results obtained by ELISA test. PCR is more sensitive and we have used it in some cases. We did not detect Bartonella agents in preparates stained by Wartin-Starr. Our study confirmed the diagnosis on basis the histological characteristics.

In milder forms, therapeutic treatment is usually supportive. Tetracycline and erythromycin may be useful. In severe forms of the disease, has recommended antibiotics: rifampicin, ciprofloxacin, trimetoprim, erythromycin, claritromycin or azithromycin. In patients with retinitis, endocarditis combinated therapy is necessary [44] [45].

In our study, the therapeutic treatment has done in all patients. generally are administered in combination with tetracycline and trimetoprim, except one case, 
which is due to unrecognized disease treated long time with tuberculostatics, and immune deficiently patients, who was treated with dual antibiotic therapy, in addition to regular antiretroviral therapy.

Untreated Bartonella infection can be fatal in HIV-infected patients as demonstrated in our study. Our patients with co-infection B. hensellae and HIV, among numerous multisystem changes, developed tumor lesions on the face, like Kaposi sarcoma, and in the purple dermal nodes sites of the thoracic and abdominal region, the histological verified as vasculitis. Vasculitis has a heterogeneous presentation, and often are accompanying by large specter of opportunistic agents. These have mediated by immunological factors or by direct vascular injured. Along with many other systemic complications, and progression, contributed to the fatal outcome of the diseased [20].

\section{Conclusions}

Montenegro is a Mediterranean country, with a significant and broad spectrum of vector borne diseases (VBD) representation, including bartonellosis. Our first experiences with this disease were focused on the detection of the most frequent manifestation of disease, cat scrach disease (CSD). But in the period from 2007 to 2015 , based on our research, we were surprised by the diversity of clinical manifestations in patients which confirmed the etiological diagnosis of bartellellosis, also found in the numerous references of other investigators in the world, and created big diagnostic, therapeutic difficulties.

It is necessary to diagnose CSD in patients with adenopathy, to differentiate CSD to a number a neoplastic diseases, examples lymphoma, leukemia, and the other neoplasm's [11] and large specter of emerging infectious diseases, example fungal infection, toxoplasmosis, tularemia, tuberculosis, plaque, lymphogranuloma venerum (LGV), AIDS, Syphilis and other. However, this can be difficult because of limitations to the currently available confirmatory diagnostic tests [12].

A small number of immune competent cases with Bartonellosis develop severe systemic disease. These may include oculoglandular syndrome, encephalitis, neuroretinitis, and pneumonia, and osteomyelitis, erythema nodosum like disease, arthritis, tuberculosis and thrombocytopenic purpura [3]-[10].

Immune deficient patients with the same organism lead to a very different disease. BA - PH is increase. Angioproliferative lesions resembling those of Kaposi sarcoma in the skin, liver, spleen, bone marrow and other organs characterizes this disease [45].

\section{Conflicts of Interest}

None to declare.

\section{References}

[1] Dehio, C. and Sander, A. (1999) Bartonella as Emerging Pathogens. Trends in Microbiology, 7, 226-228. https://doi.org/10.1016/S0966-842X(99)01523-1 
[2] Chomel, B.B. and Kasten, R.W. (2010) Bartonellosis, an Increasingly Recognized Zoonosis. Journal of Applied Microbiology, 109, 743-750. https://doi.org/10.1111/j.1365-2672.2010.04679.x

[3] Breitschwerdt, E.B., Maggi, R.G., Chromel, B.B., et al. (2010) Bartonellosis: An Emerging Infectious Disease of Zoonotic Importance to Animals and Human Beings. Journal of Veterinary Emergency and Critical Care, 20, 8-30. https://doi.org/10.1111/j.1476-4431.2009.00496.x

[4] Boulouis, H.J., Chang, C.C., Henn, J.B., Kasten, R.W. and Crommel, B.B. (2005) Factors Associated with the Rapid Emergence of Zoonotic Bartonella Infections. Veterinary Research, 36, 383-410. https://doi.org/10.1051/vetres:2005009

[5] Maguina, C. and Gotuzzo, E. (2000) Bartonellosis New and Old Infectious Diseases. Medical Clinics of North America, 14, 1-22.

[6] Breitschwerdt, E.B. (2014) Bartonellosis: One Health Perspectives for an Emerging Infectious Desseases. ILAR Journal, 55, 46-48. https://doi.org/10.1093/ilar/ilu015

[7] Drancourt, M., Birtles, R., Chaumentin, G., Vandenesch, F., Etienne, J. and Raoult, D. (1996) New Serotype of Bartonella Henselae in Endocarditis and Cat-Scratch Disease in Endocarditis and Cat-Scratch Disease. The Lancet, 347, 441-443. https://doi.org/10.1016/S0140-6736(96)90012-4

[8] Chomel, B.B., Boulouis, H.J., Breitschwerdt, EB., et al. (2009) Ecological Fitness and Strategies of Adaptation of Bartonella Species to Their Hosts and Vectors. Veterinary Research, 40, 29. https://doi.org/10.1051/vetres/2009011

[9] Kosoy, M., Bai, Y., Lyndi, T., Kuymin, I., Niezgoda, M., Franka, R., Aqwanda, B., Breiman, R. and Rupeerecht, R. (2010) Bartonella spp. in Bats, Kenya. Emerging Infectious Diseases, 16, 1875-1881. https://doi.org/10.3201/eid1612.100601

[10] Diaz, M.H., Baty, Y., Malania, L., Winchell, J.M. and Kosay, M.Y. (2012) Development of a Novel Genus Species and Genotypes. Journal of Clinical Microbiology, $50,1186$.

[11] Maggi, R.G., Kosoy, M., Mintzer, M. and Breischwerdt, E.B. (2009) Isolation of Candidatus Bartonella melophagi from Human Blood. Emerging Infectious Diseases, 15, 66-68. https://doi.org/10.3201/eid1501.081080

[12] Lin, E.Y., Tsigrelis, C., Baddour, L.M., Lepidi, H., Rolain, J.M., Patel, R., et al. (2010) Candidatus Bartonella mayotimonensis and Endocarditis. Emerging Infectious Diseases, 16, 500-503. https://doi.org/10.3201/eid1603.081673

[13] Mulinsk, K.E., Hang, J., Jiang, J., et al. (2013) Molecular Typing of "Candidates Bartonella ancashi”, a New Human Pathogen Causing Verruga Peruana. Journal of Clinical Microbiology, 51, 3865-3881. https://doi.org/10.1128/JCM.01226-13

[14] Bass, J.W., Vincent, J.M. and Person, D.A. (1997) The Expanding Spectrum of Bartonella Infections: II. Cat Scrach Disease. The Pediatric Infectious Disease Journal, 16, 157-163. https://doi.org/10.1097/00006454-199702000-00002

[15] Vander Heyden, T.R., Young, S.L., Breitschwerdt, E.B., et al. (2012) Granulomatous Hepatitis Due to Bartonella hensellae Infection in an Immune-Competent Patient. BMC Infectious Diseases, 12, 17.

[16] Leong, S.S., Cazen, R.A., Yu, G.S., et al. (1992) Bartonella henselae Species nov a Cause of Septicemia, Bacillary Angiomatosis and Parenchymal Bacillary Peliosis. Journal of Clinical Microbiology, 30, 275-280.

[17] Marie, J.L., Fournie, P.E., Rolain, J.M., Briolant, S., Daoust, B. and Raoult, D. (2006) Molecular Detection of B. quintana, B. elisabete, B. koehleae, B. doshine, B. taylorii and $R$. felis in Rodents, Fleas Collected in Kabul, Afganistan. The American Journal 
of Tropical Medicine and Hygiene, 74, 436-439. https://doi.org/10.4269/ajtmh.2006.74.436

[18] Inone, K., Kabeya, H., Hiratory, H., Ueda, K., Kosay, M., Chromel, B., Boulouis, H. and Maruyama, S. (2010) Bartonella japonica sp. Now and Bartonella silvatica sp. Now Isolated from Apodemus Mice. International Journal of Systematic and Evolutionary Microbiology, 60, 759-763. https://doi.org/10.1099/ijs.0.011528-0

[19] Gundi, V., Taylor, C., Raoult, D. and La Scola, B. (2009) Bartonella rattaustralieni sp. Now, Bartonella queendensis spp. Now and Bartonella coopersplainsensis spp. Now, Identifier in Australian Rats. 59, 2956-2961.

[20] Podsiadly, E., Chmielewski, T. and Tylewska-Weirzbanowska, S. (2003) Bartonella hensellae and Borrelia burgdorferi Infections of the Central Nervous System. Annals of the New York Academy of Sciences, 990, 404-406.

[21] Maggi, R.G., Mozayeni, B.R., Pultorak, E.L., et al. (2012) Bartonella Species Bacteriemia and Rheumatic Symptoms in Patients from Lyme Disease Endemic Region. Emerging Infectious Diseases, 18, 783-791. https://doi.org/10.3201/eid1805.111366

[22] Siciliano, R.F., Strabelli, T.M., Zeigler, R., et al. (2006) Infective Endocarditis Due to Bartonella Species and Coxiella burnetii: Experience at a Cardiology Hospital in Sao Paulo, Brasil. Annals of the New York Academy of Sciences, 1078, 215-222. https://doi.org/10.1196/annals.1374.123

[23] Shahss, S.S. and Mc Gowan, J.P. (2003) Rickettsial, Ehrlichial and Bartonella Infections of the Myocardium and Pericardium. Frontiers in Bioscience, 8, 291-297.

[24] Berghoff, W. (2012) Chronic Lyme Disease and Co-Infections: Differential Diagnosis. The Open Neurology Journal, 6, 158-178. https://doi.org/10.2174/1874205X01206010158

[25] Carithers, H.A. (1970) Cat-Scratch Disease: Notes on Its History. American Journal of Diseases of Children, 119, 200-203. https://doi.org/10.1001/archpedi.1970.02100050202002

[26] Lamps, L.W. and Scott, M.A. (2004) Cat-Scratch Disease: Historic, Clinical, and Pathologic Perspectives. American Journal of Clinical Pathology, 121, 571-581. https://doi.org/10.1309/JC8YM53L4E0L6PT5

[27] Chain, K.S. and Kosoy, M. (2010) Analysis of Multi-Stain Bartonella Pathogens in Natural Host Population-Do They Behave as Species or Minor Genetic Variants? Epidemics, 2, 165-172. https://doi.org/10.1016/j.epidem.2010.08.002

[28] Adamska, M. (2010) Bartonella Species as a Zoonotic Pathogens Transmiting by Blood-Feeding. Wiadomości Parazytologiczne, 56, 1-9.

[29] Izri, A., Depaquit, J. and Parola, P. (2006) Phlebotominae sandfly and Transmission of Disease Agents Arund the Mediteranean Basin. Médecine Tropicale: Revue du Corps de santé colonial, 66, 249-435.

[30] Mosbacher, M.E., Klotz, S. and Pinnas, J.Z. (2011) Bartonella henselae and the Potential for Arthropod Vector Borne Transmission. Vector-Borne and Zoonotic Diseases, 11, 471-477. https://doi.org/10.1089/vbz.2010.0106

[31] Kim, C.M., Kim, J.Y., Yi, Y.H., Lee, M.R., Cho, M.R., Shah, D.H., et al. (2005) Detection of Bartonella Species from Tick, Mites and Small Mammals in Korea. Journal of Veterinary Science, 6, 327-334.

[32] Swanson, S.J., Neitzel, D., Reed, K.D. and Belongia, E.A. (2006) Coinfections Acquired from Ixodes Ticks. Clinical Microbiology Reviews, 19, 708-727. https://doi.org/10.1128/CMR.00011-06

[33] Alsmark, C.M., Frank, A.C., Karlberg, E.O., Legault, B.A., Ardell, D.H., Canback, B., 
Erikson, A.S., Naslund, A.K., Handley, S.A., Huvet, M., La Scola, B., Holmberg, M. and Anderson, S.G. (2004) The Louse-Borne Human Pathogen Bartonella quintana Is a Genomic Derivative of the Zoonotic Agent Bartonella henselae. Proceedings of the National Academy of Sciences of the United States, 101, 9716-9721. https://doi.org/10.1073/pnas.0305659101

[34] Hercik, K., Hasova, V., Janecek, J. and Branny, P. (2007) Molecular Evidence of Bartonella DNA in Ixodes Ticks in Czechia. Folia Microbiologica, 52, 503-509. https://doi.org/10.1007/BF02932111

[35] Cotté, V., Bonnet, S., Le Rhun, D., Le Naour, E., Chauvin, A., Boulouis, H.J., et al. (2008) Transmission of Bartonella henselae by Ixodes ricinus. Emerging Infectious Diseases, 14, 1074-1080. https://doi.org/10.3201/eid1407.071110

[36] La Scola, B., Holmberg, M. and Raoult, D. (2004) Lack of Bartonella Species in 167 Ixodes ricinus Ticks Collected in Central Sweden. Scandinavian Journal of Infectious Diseases, 36, 305-306. https://doi.org/10.1080/00365540410020145

[37] Schouls, L.M., Van De Pol, I., Rijpkema, S.G. and Schot, C.S. (1999) Detection and Identification of Ehrlichia, Borrelia burgdorferi sensu lato, and Bartonella Species in Dutch Ixodes ricinus Ticks. Journal of Clinical Microbiology, 37, 2215-2222.

[38] Liston, T.E. and Koechler, J.E. (1996) Granulomatous Hepatitis and Necrotizing Splenitis Due to Diagnosed with Chronic Lyme Disease: A Systematic Literature Review of Hepatosplenic Manifestations of Bartonella Infection. Clinical Infectious Diseases, 22, 951-957. https://doi.org/10.1093/clinids/22.6.951

[39] Paul, M., Lantos, M.D., Gary, P. and Wormser, M.D. (2014) Chronic Coinfections in Patients Diagnosed with Chronic Lyme Disease: A Systematic Literature Review. American Journal of Medicine, 127, 1105-1110. https://doi.org/10.1016/j.amjmed.2014.05.036

[40] Welc-Faleciak, R., Hildevbrandt, A. and Sinski, E. (2010) Co-Infection with Borrelias Species and Other Tick-Borne Pathogens in Humans, Two Cases from Poland. Annals of Agricultural and Environmental Medicine, 17, 303-313.

[41] Hornef, M.W., Wick, M.J., Rhen, M. and Normaek, S. (2002) Bacterial Strategies for Overcoming Host Innate and Adaptive Immune Responss. Nature Immunology, 3, 1033-1040. https://doi.org/10.1038/ni1102-1033

[42] Eskswo, E., Rao, R.V. and Mordechia, E. (2001) Concurrent Infection of the Central Nervous System by Borrelia burgdorferi and Bartonella henselae: Evidence for a Novel Tick-Borne Disease Complex. Archives of Neurology, 58, 1357-1363. https://doi.org/10.1001/archneur.58.9.1357

[43] Pons, I., Sanfeliu, I., Cardeñosa, N., Nogueras, M.M., Font, B. and Segura, F. (2008) Serological Evidence of Bartonella henselae Infection in Healthy People in Catalonia, Spain. Epidemiology \& Infection, 136, 1712-1716. https://doi.org/10.1017/S0950268808000368

[44] Maurin, M. and Raoult, D. (1998) Bartonella Infections: Diagnostics and Management Issues. Current Opinion in Infectious Diseases, 11, 189-193. https://doi.org/10.1097/00001432-199804000-00018

[45] Iannaccone, R., Federle, M.P., Brancatelli, G., et al. (2006) Peliosis Hepatis: Spectrum of Imaging Findings. American Journal of Roentgenology, 187, W43-W52.

[46] Koehler, J.E., Sanchez, M.A., Garrido, C.S., Whitfeld, M.J., Chen, F.M., Berger, T.G., Rodriguez-Barradas, M.C., Le Boit, P.E. and Tappero, J.W. (1997) Molecular Epidemiology of Bartonella Infections in Patients with Bacillary Angiomatosis-Peliosis. The New England Journal of Medicine, 337, 1876-1883. https://doi.org/10.1056/NEJM199712253372603 
[47] Ahsan, N., Holman, M.J., Riley, T.R., et al. (1998) Peloisis Hepatis Due to Bartonella henselae in Transplantation: A Hemato-Hepato-Renal Syndrome. Transplantation, 65, 1000. https://doi.org/10.1097/00007890-199804150-00024

[48] Plettenberg, A., Lorenzen, T., Burtsche, B.T., et al. (2000) Bacillary Angiomatosis in HIV-Infected Patients-An Epidemiological and Clinical Study. Dermatology, 201, 326. https://doi.org/10.1159/000051547 


\section{Appendix}

\section{Original Photo of Our Patients}

Pathohystological diagnosis of CSD by Prof. Dr. Mileta Golubovic.

DG: Lymphadenitis chronic granulomatosa (precipue suppurativa).

Macroscopic: More lymph nodes, the largest diameter of $3 \times 2.4 \mathrm{~cm}$. On the cross sections is observed more whitish, medium-hard fine focus with central areas of necrosis.

Microscopic: Described formation identifies a necrotic granuloma, built of epithelioid histiocytes, rare few multinucleate giant cells and lymphocytes, surrounded by concentric hyalinised binder.

Present peripheral large star-formation in whose centers of mass with abundant eosinophyls granulocytes nuclear detritus (dominance neutrophyls).

Conclusion: The morphology of granulomas inflammation in the first place corresponds to of cat scratch disease (CSD).
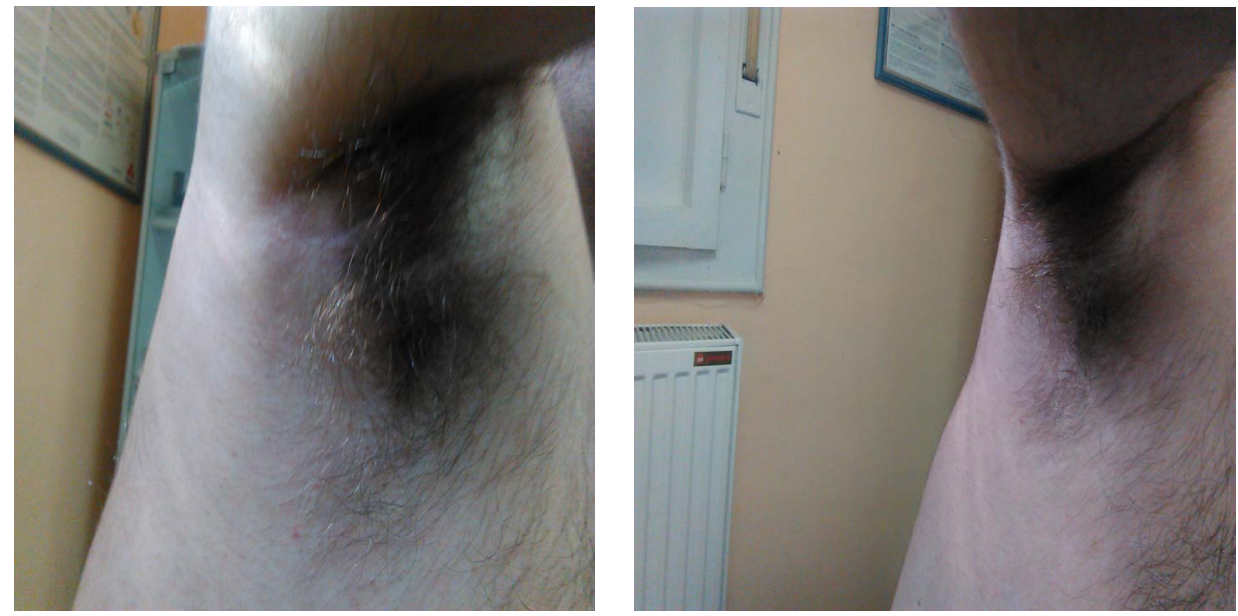

Original US Diagnosis by Dr. Mosa Markovic
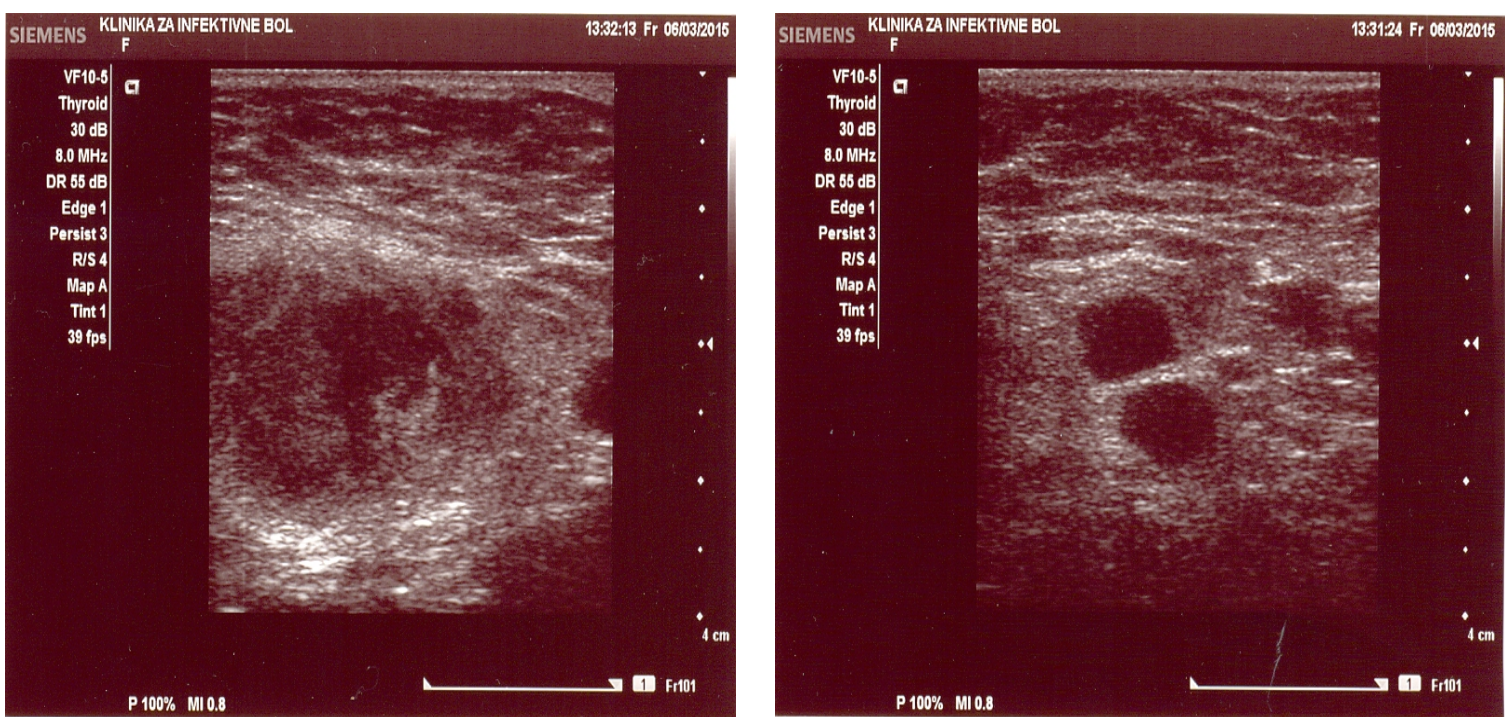


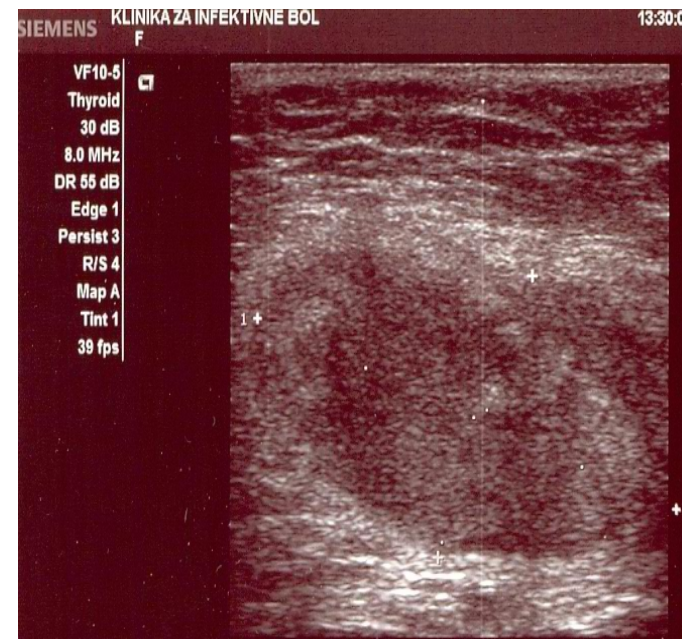

$D 1=38.6 \mathrm{~mm}$

$D=21.1 \mathrm{~mm}$
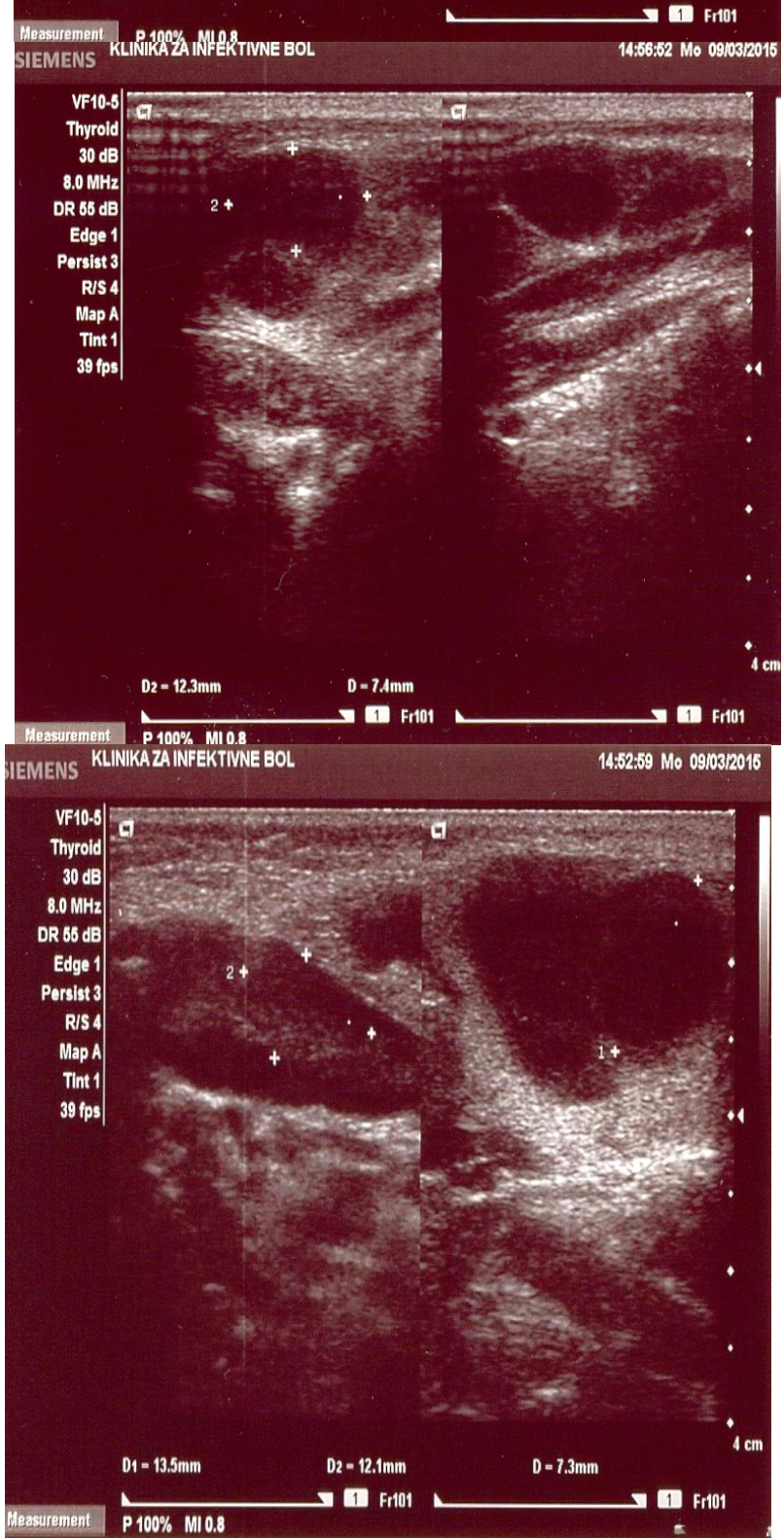

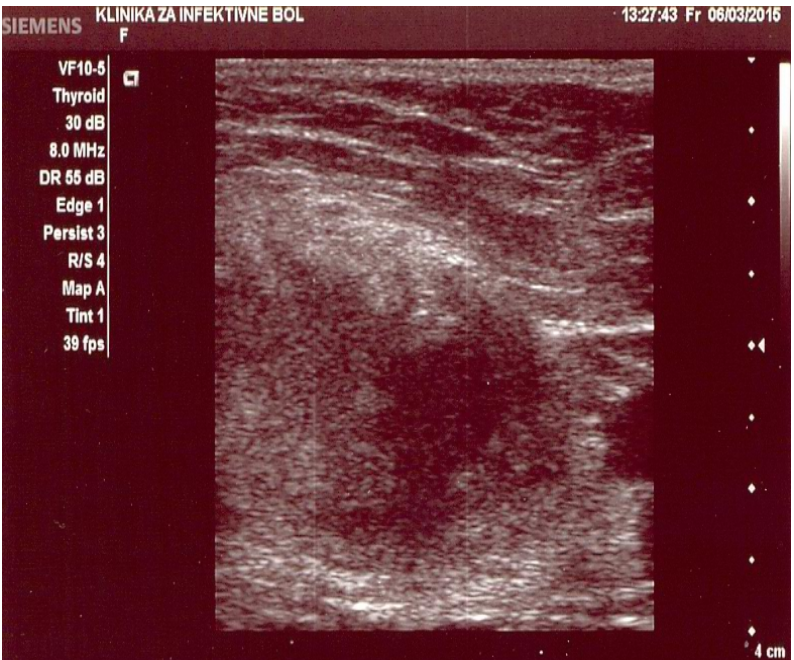

- 11 Fr101
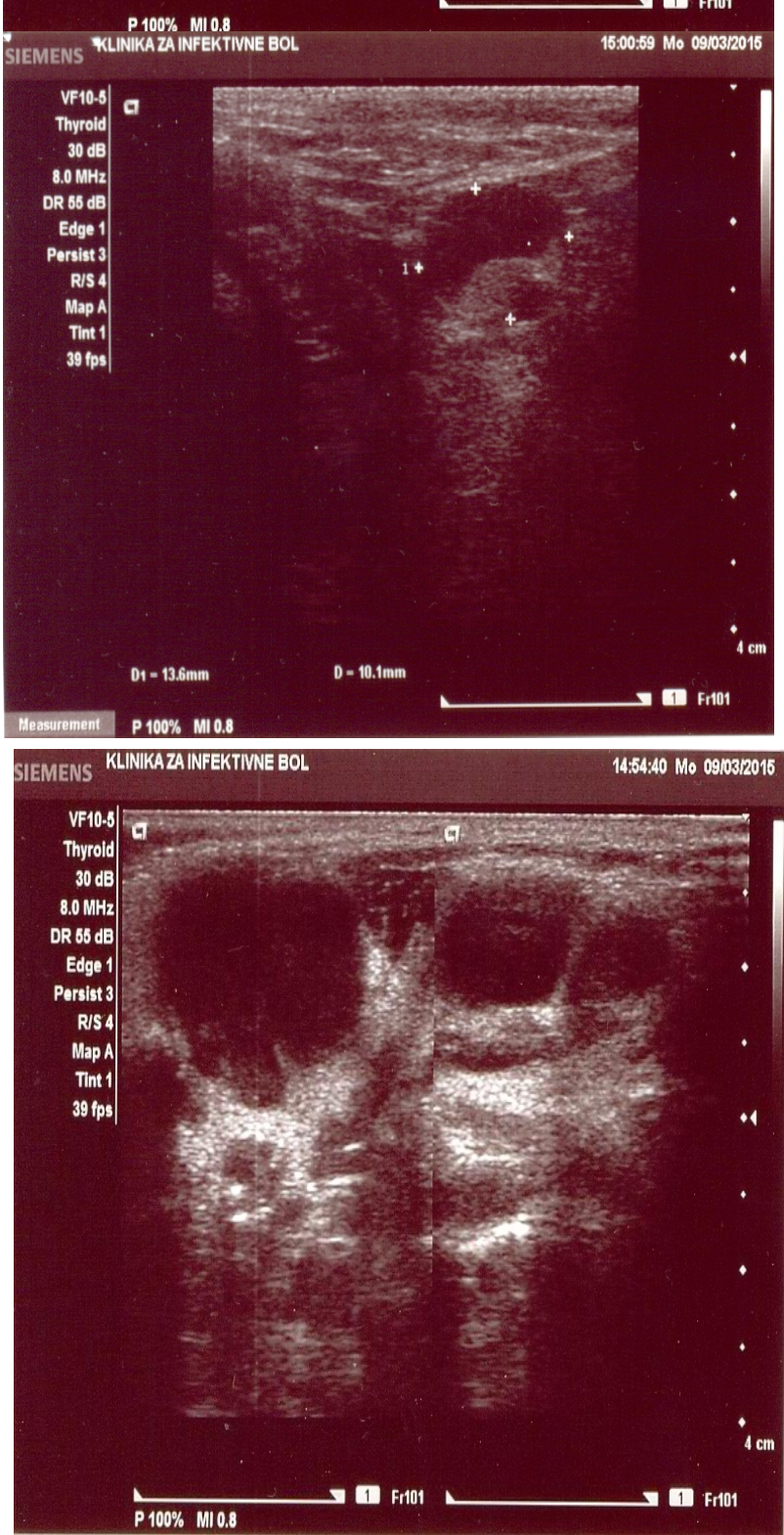

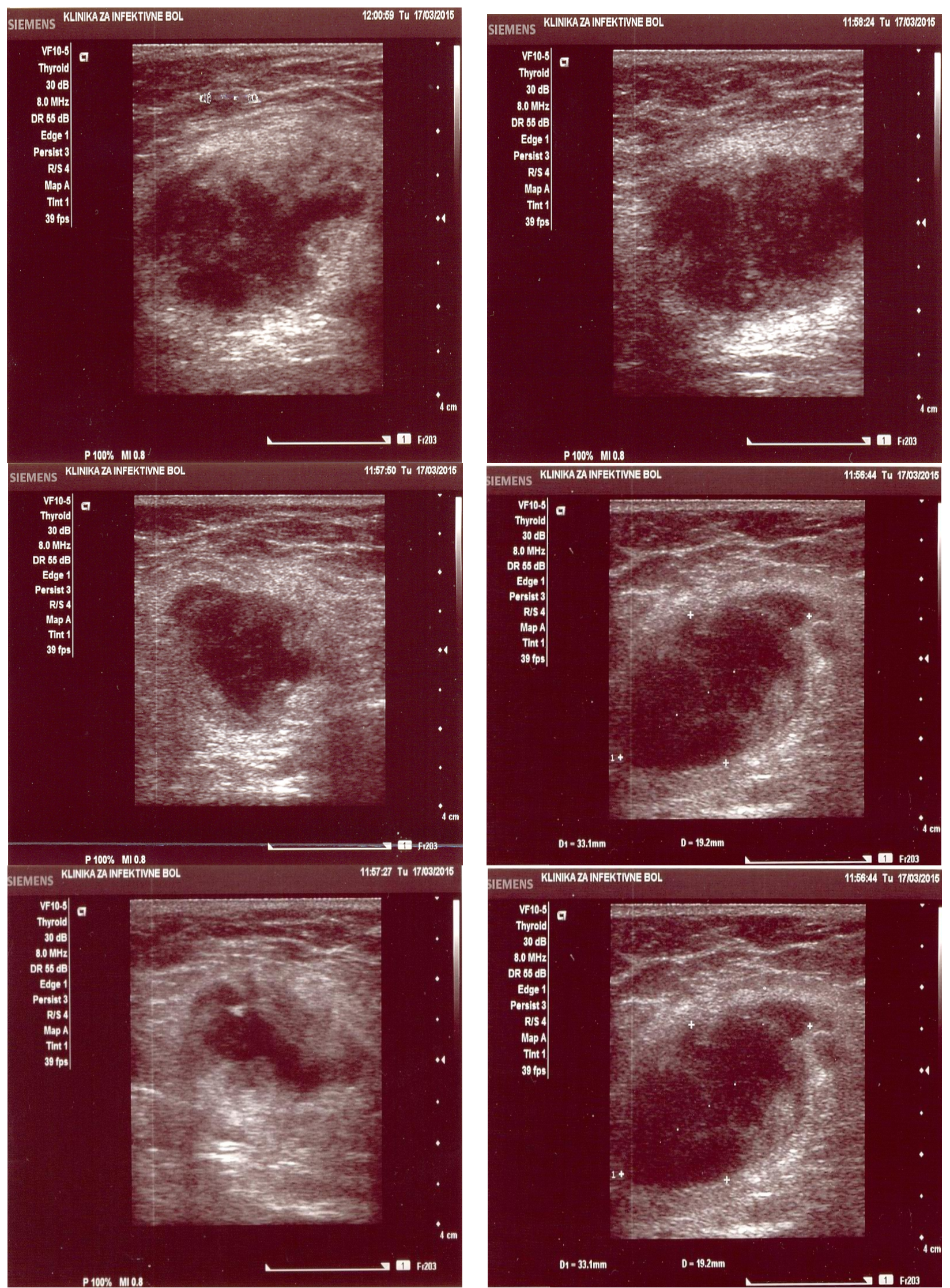


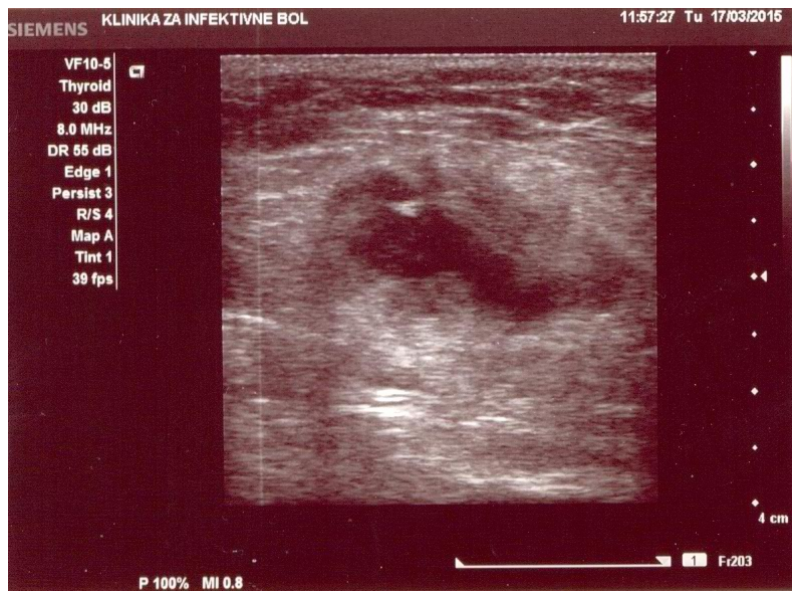

For all of our research, photos, additional investigations (ex. patohistological), we had the permission of our patients.

\section{Ethical Considerations}

All experiments were carried out in compliance with the relevant laws and guidelines, in accordance with the ethical standards of the Declaration of Helsinki. 